\title{
Blood loss assessment in abdominal hysterectomy: how accurate?
}

\section{Virupaksha Ajjammanavar*, Jayashree S., Amrutha B.}

Department of OBG, JSS Medical College, JSS University, Mysore, Karnataka, India

Received: 21 October 2015

Accepted: 12 December 2015

\author{
*Correspondence: \\ Dr. Virupaksha Ajjammanavar, \\ E-mail: drvirupakshaa@yahoo.co.in
}

Copyright: ( ) the author(s), publisher and licensee Medip Academy. This is an open-access article distributed under the terms of the Creative Commons Attribution Non-Commercial License, which permits unrestricted non-commercial use, distribution, and reproduction in any medium, provided th e original work is properly cited.

\begin{abstract}
Background: Precise estimation of blood loss is the key to optimal transfusion practice in surgery. Many studies done in various fields of surgery infer that clinical assessment of blood loss by the surgeon or anesthesiologist is inaccurate. The purpose of this study is to see if there is any difference in visual estimation of blood loss and actual blood loss calculated using modification of gross formula in abdominal hysterectomy.

Methods: Fifty four patients undergoing total abdominal hysterectomy for various indications at JSS Hospital, Mysore were included in the study. Baseline characteristics, pre-operative haematocrit, clinically estimated blood loss (EBL) and post-operative haematocrit were noted. Actual blood loss (ABL) was calculated from a modification of the Gross formula. The number of cases where the blood loss was clinically underestimated and overestimated; and the relationship between the difference in actual and estimated blood loss and accuracy of clinical assessment of blood loss was determined. The data obtained was analysed using descriptive statistics and Crammer's V test.

Results: In the 54 cases of abdominal hysterectomy which we studied, there was overestimation of blood loss in 28 $(51.9 \%)$ cases and underestimation of blood loss in $26(48.1 \%)$ cases. The more the inaccuracy in clinical assessment of blood loss, more was the possibility of clinicians underestimating the blood loss.

Conclusions: Clinical estimation of blood loss is an inaccurate method of assessing blood loss in abdominal hysterectomy.
\end{abstract}

Keywords: Abdominal hysterectomy, Estimated blood loss, Actual blood loss

\section{INTRODUCTION}

Estimation of surgical blood loss influences clinical management involving blood transfusion and its potential complications. Blood is a finite resource with a limited shelf life and is associated with considerable processing costs. ${ }^{1}$ Utilization of this resource needs critical review to identify areas of overuse and thus reduce risk to patient and hospital costs. Risks of homologous transfusion vary in type and severity. Morbidity and mortality may result from either an immunologically mediated reaction or a transmitted infection. ${ }^{2}$

Consultants often rely on clinical estimation of blood loss alone to guide transfusion of red blood cells in the preoperative period because other methods of examination may be either impractical or unavailable all the time. ${ }^{3}$ Mathematical models, such as those proposed by Brecher et al have reported that calculations of blood loss were on an average 2.1 times greater than the estimated blood loss provided by anesthesia. ${ }^{4}$ Gravimetric methods have also been reported. Lee et al compared gravimetric and laboratory methods of quantifying blood loss during animal surgery. Intraoperative blood loss was first quantified by measuring irrigation fluid and the weight of surgical sponges. Blood loss was determined as the weight difference between the sterile saline solution used and gauze sponges pre and post-operatively. A highly significant correlation was found between the laboratory method and the gravimetric method, supporting the use of weight measurement as an accurate option. ${ }^{5}$ 
The extent of blood loss and response to transfusion is reflected in the changes in the hematocrit. This change may be used to calculate the actual blood loss using suitable formulae. In our study, we have used the modification of gross formula to calculate the actual blood loss. 6

\section{METHODS}

This is a prospective study of 54 patients undergoing total abdominal hysterectomy for various indications at JSS Hospital, Mysore. Patients with BMI more than 25 and those with anemia or sudden and/or massive blood loss were excluded from the study. This is because blood volume estimation from body weight becomes inaccurate if BMI is more than 25. Also, application of the formula for calculation of blood loss requires normovolemia to be maintained throughout which is not possible with RBC transfusion. Hence patients with anemia or sudden and/or massive blood loss who would require transfusion were excluded from the study.

Baseline characteristics like age, weight, BMI and indication for hysterectomy were noted. Pre-operative haematocrit was measured. Post-operative haematocrit was measured 24 hours after surgery.

Blood loss assessment was done clinically by counting the blood soaked mops and gauze pieces and multiplying them by the estimated volume of blood they carried and by measuring the volume of blood in suction bottle. This was labelled as estimated blood loss (EBL).

Actual blood loss (ABL) was calculated from a modification of the gross formula.

Actual blood loss $=\mathrm{BV}\{\operatorname{Hct}(\mathrm{i})-\operatorname{Hct}(\mathrm{f})\} / \operatorname{Hct}(\mathrm{m})$

BV: Blood volume.

Blood volume is calculated from the body weight by using following formula.

Blood volume $=$ Body weight $($ in $\mathrm{Kg}) \times 70$
Hct (i): Initial hematocrit

Hct (f): Final hematocrit

Hct (m): Mean hematocrit

Based on the ABL, three groups were formed, one with ABL less than $250 \mathrm{ml}$, second with ABL between 250 and $500 \mathrm{ml}$ and the third group with ABL more than 500 $\mathrm{ml}$. In each of these three groups, we noted the number of cases where the blood loss was underestimated $(\mathrm{EBL}<\mathrm{ABL})$ or overestimated $(\mathrm{EBL}>\mathrm{ABL})$ by clinical estimation.

The difference between ABL and EBL was determined for each case. In both the underestimated as well as overestimated cases, it was determined in what percent of cases the blood loss difference was less than $250 \mathrm{ml}$, between 250 and $500 \mathrm{ml}$ and more than $500 \mathrm{ml}$.

The data obtained was analysed using descriptive statistics and Crammer's V test.

\section{RESULTS}

The age of the patients undergoing abdominal hysterectomy ranged from 30 to 55 years, with the mean age being 42.8 years. The average BMI was $24.22 \mathrm{~kg} / \mathrm{m}^{2}$, the lowest being $15.4 \mathrm{~kg} / \mathrm{m}^{2}$ and the highest being 37.5 $\mathrm{kg} / \mathrm{m}^{2}$. The size of uterus ranged from normal size to 26 weeks. Majority of women underwent hysterectomy for fibroid uterus (55.6\%). The next common indication was DUB (18.5\%) followed by adnexal pathology (11.1\%), adenomyosis $(7.4 \%)$ and endometrial hyperplasia (7.4\%).

It is evident from table 1 that when the actual blood loss is less than $250 \mathrm{ml}$, there is overestimation of blood loss clinically but as the blood loss increases, there is a tendency to clinically underestimate the blood loss. In the group where the actual blood loss was between 250 and $500 \mathrm{ml}$, blood loss was overestimated in $31.6 \%$ of cases and underestimated in $68.4 \%$ of cases. In all the 9 cases where actual blood loss was more than $500 \mathrm{ml}$, blood loss was underestimated. This difference was statistically different with a $\mathrm{p}$ value of 0.000 .

Table 1: Actual blood loss.

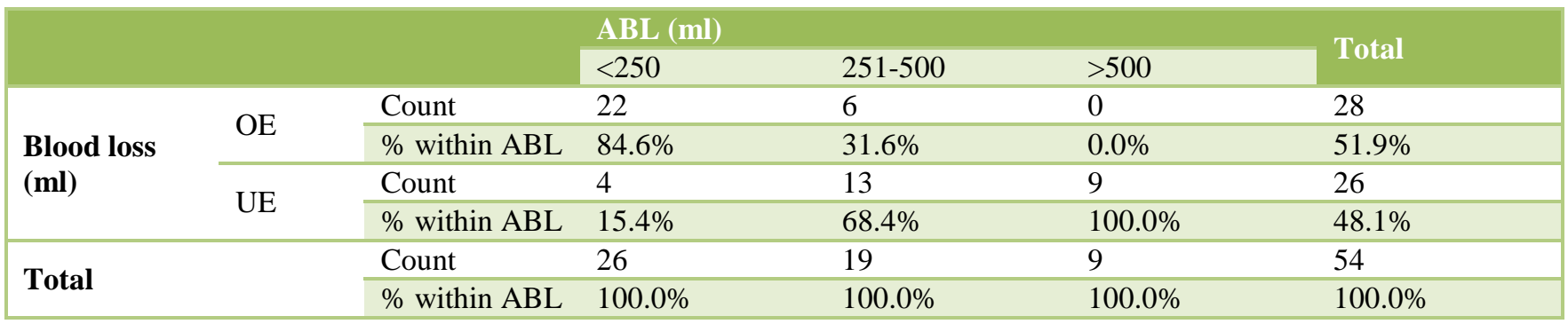

p: 0.000, ABL: Actual blood loss, OE: Overestimation, UE: Underestimation 
Table 2: Difference between the ABL and EBL in each case.

\begin{tabular}{|c|c|c|c|c|c|}
\hline & & & Group & & \\
\hline & & & UE & $\mathrm{OE}$ & Total \\
\hline & 251 to 500 & Count & 25 & 0 & 25 \\
\hline & -251 to 500 & $\%$ within group & $89.3 \%$ & $0.0 \%$ & $46.3 \%$ \\
\hline & $1+5250$ & Count & 3 & 0 & 3 \\
\hline & -1 to 250 & $\%$ within group & $10.7 \%$ & $0.0 \%$ & $5.6 \%$ \\
\hline EBL-ABL & 1250 & Count & 0 & 22 & 22 \\
\hline$(\mathbf{m l})$ & $1-250$ & $\%$ within group & $0.0 \%$ & $84.6 \%$ & $40.7 \%$ \\
\hline & 251500 & Count & 0 & 3 & 3 \\
\hline & $251-500$ & $\%$ within group & $0.0 \%$ & $11.5 \%$ & $5.6 \%$ \\
\hline & 5001 & Count & 0 & 1 & 1 \\
\hline & $500+$ & $\%$ within group & $0.0 \%$ & $3.8 \%$ & $1.9 \%$ \\
\hline Totol & & Count & 28 & 26 & 54 \\
\hline Iotal & & $\%$ within group & $100.0 \%$ & $100.0 \%$ & $100.0 \%$ \\
\hline
\end{tabular}

p: 0.000, EBL: Estimated Blood Loss, ABL: Actual Blood Loss, UE: Underestimation, OE: Overestimation

Further, when we calculated the difference between the $\mathrm{ABL}$ and EBL in each case, we found that the difference in blood loss ranged from 250 to $500 \mathrm{ml}$ in $89.3 \%$ of cases where blood loss was underestimated as opposed to only $11.5 \%$ in those cases where blood loss was overestimated. In majority of cases where the blood loss was overestimated (84.6\%), the difference between actual blood loss and estimated blood loss was less than $250 \mathrm{ml}$. This difference was also statistically significant. In the whole study, the difference in blood loss exceeded 500 $\mathrm{ml}$ in only one case where there was overestimation of blood loss. This indicates that there is a tendency to underestimate blood loss when the difference between actual and estimated blood loss is more than $250 \mathrm{ml}$. (Table 2)

\section{DISCUSSION}

There are not many studies regarding accurate estimation of blood loss in abdominal hysterectomy. Although blood transfusion may not be required in a majority of cases of hysterectomy, defining transfusion triggers for RBC transfusions is important to avoid unnecessary RBC transfusions as well as to avoid under-transfusion in some situations where RBC transfusion would be beneficial.

Various methods of blood loss measurement have been suggested. These include subjective estimation which is highly unreliable and objective methods such as gravimetric methods (swab weighing, weighing the patient etc.), automated blood loss meter based on electrolyte conductivity, calorimetric method and measuring the radioactivity of blood. ${ }^{7}$ There is currently no clear, concise method for predicting intra-operative blood loss.

While the current literature is sparse with low levels of significance, there are certain mathematical models that can be incorporated as a tool. However, there is a need for more randomized prospective clinical trials to further define clear objective measures.
Lee et al concluded that quantifying intra-operative blood loss using spectrophotometric hemoglobin analysis accurately assessed the amount of blood loss; however, it is a time-consuming procedure, primarily applicable as a research tool. Gravimetric evaluation of intra-operative blood loss was found to be an accurate method, which can be recommended for use in a clinical setting.

Howe and colleagues showed that the mean difference of preoperative hemoglobin vs. postoperative hemoglobin was $3.3 \mathrm{~g} / \mathrm{dL}$ (SD 2.1). In their retrospective study, clinical estimation of blood loss, using a multiple linear regression model, was closely correlated with actual change in pre-operative hemoglobin. While this offers some insight into the change in hemoglobin with surgery, it fails to clarify the accurate methods of estimating blood loss itself. This study does, however confirm the validity of EBL and its significance as it directly correlates as a predictor of change in hemoglobin. ${ }^{8}$

In our study, we found that there was underestimation of blood loss in $48.1 \%$ of cases of abdominal hysterectomy and overestimation in $51.9 \%$. Ganesan Ganesan Ram et $\mathrm{al}^{3}$ in their study on blood loss in hip or knee replacement surgeries found that $70 \%$ of patients had their blood loss underestimated. Naveen Eipe et $\mathrm{al}^{2}$ found in their study on pre-operative blood loss that there was underestimation of blood loss in $64 \%$ of cases.

Also, when there was excess intra-operative blood loss there was a tendency to underestimate blood loss by the clinicians. Naveen Eipe et $\mathrm{al}^{2}$ in their study found that clinical estimation is inaccurate as the blood loss increases. Ganesan et $\mathrm{al}^{3}$ in their study also found similar results.

\section{CONCLUSIONS}

In conclusion, inaccurate estimates of surgical blood loss may adversely affect the patient's well-being in intra- and postoperative care. Most surgeons continue to report their 
surgical blood loss by estimating the volume of blood in the suction container and the amount of blood lost in surgical laparotomy pads, which, though convenient, is inaccurate. Modified gross formula can be used as an economical and accurate method to estimate blood loss in operative procedures.

\section{ACKNOWLEDGEMENTS}

Our sincere thanks to Dr. Ambarisha Bhandiwad, Dr. Anjali Siddesh, Dr. Sujatha MS and Dr. Nandeesh Manoli for their constant encouragement and support.

Funding: No funding sources Conflict of interest: None declared

Ethical approval: Not required

\section{REFERENCES}

1. Mc Swiney MM, O’Farrell D, Joshi GP, Mc Carroll SM. Blood Transfusion in Total Hip Athroplasty: guidelines to eliminate over transfusion. Can J Anaesth. 1993;40(3): 222-26.
2. Naveen Eipe, Manickam Ponniah. Perioperative blood loss assessment - How accurate? Indian $\mathbf{J}$ Anaesth. 2006;50(1):35-8.

3. Ganesan R, P Suresh, Phagal Varthi V. Surgeons often underestimate the amount of blood loss in replacement surgeries. Chinese J Traumatol. 2014;17(4):225-8.

4. Brecher M, Monk T, Goodnough L. A Standardized method for calculating blood loss, Transfusion. 1997;37:1070-74.

5. Lee MH, Ingvertsen BT, Kirpensteign J, Jensen AL. Quantification of Surgical Blood Loss. Vet Surg. 2006;35:388-93.

6. Gross JB. Estimating allowable blood loss: corrected for dilution. Anesthesiol. 1983;58(3):277-80.

7. Thornton JA, Saynor R, Schroeder HG, Taylor DG, Verel D. (1963) Estimation of blood loss with particular reference to cardiac surgery: description of a method. British J Anaesth. 1963;35:91-9.

8. Howe C, Paschall C, Panwalker A, Beal J. A model for clinical estimation of perioperative hemorrhage. Clin Appl Thrombosis/Hemostasis. 2003;9(2):131-5.

Cite this article as: Ajjammanavar V, Jayashree S, Amrutha B. Blood loss assessment in abdominal hysterectomy: how accurate? Int J Reprod Contracept Obstet Gynecol 2016;5:306-9. 